To cite this article: Yıldız O, Çapçı, Ünlü A, Şimşek B, Paşaoğlu I. Erişkin hastalarda kardiyopulmoner-bypass sonrası gelişen akut böbrek hasarının erken tanısında Neutrophil gelatinase-associated lipocalin ve sistatin C'nin önemi. Turk J Clin Lab 2019; 10: 142-148.

- Orjinal Makale

\title{
Erişkin hastalarda kardiyopulmoner-bypass sonrası gelişen akut böbrek hasarının erken tanısında neutrophil gelatinase-associated lipocalin ve sistatin C'nin önemi
}

\section{Importance of neutrophil gelatinase-associated lipocalin and cystatin C in early diagnosis of cardiopulmonary bypass associated acute kidney injury in adult patients}

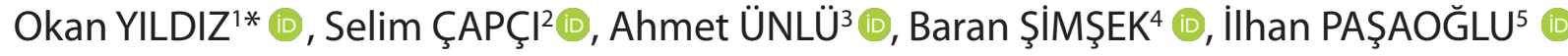

'Sağlık Bilimleri Üniversitesi Mehmet AkifErsoy Eğitim Araştırma Hastanesi, Çocuk Kalp Damar Cerrahisi Kliniği, İstanbul/TÜRKiYE

${ }^{2}$ Tire Devlet Hastanesi, Kalp Damar Cerrahisi Kliniği, İzmir/TÜRKIYE

${ }^{3}$ Medical Park Uşak Hastanesi, Kalp Damar Cerrahisi Kliniği, Uşak/TÜRKiYE

${ }^{4}$ Çanakkale Mehmet Akif Ersoy Devlet Hastanesi, Kalp Damar Cerrahisi Kliniği, Çanakkale/TÜRKiYE

${ }^{5}$ Hacettepe Üniversitesi Tıp Fakültesi, Kalp ve Damar Cerrahisi Anabilim Dalı Ankara/TÜRKIYE

\section{Öz}

Amaç: Kardiyopulmoner bypass sonrası oluşan akut böbrek hasarı (CPB-ABH) mortalite ve morbidite artışı ile ilişkilidir. Postoperatif dönemde $A B H$ erken tanısını sağlayacak biyobelirteçler tedavi başarısını artırabilir. Bu çalışmanın amacı neutrophil gelatinase-associated lipocalin (NGAL) ve sistatin C (Cys $C$ ) seviyelerini ölçmek ve erken biyobelirteç olarak doğruluk ve güvenilirliği test etmektir.

Gereç ve Yöntemler: Çalışmamı CPB kullanılarak uygulanan kalp cerrahisi sonrası ABH gelişen hastalarda kreatinin, NGAL ve Cys $C$ düzeylerini karşılaştıran prospektif gözlemsel bir çalışmadır. Kırk üç hasta çalışmaya dâhil edildi. CPB'nin başlatılmasından sonra, önceden belirlenmiş iki zaman noktasında (6 ve 24 saat) NGAL ve Cys C için kan örnekleri alındı.

Bulgular: AKIN sınıflamasına göre, 8 hasta (\% 44) ABH gelişti, 35 (\% 56) hastada ABH gözlenmedi. Tüm parametreler için işletim karakteristiği eğrisi altında kalan alan (AUCROC) hesaplandı. AUCROC değeri 6.saat NGAL için 0,81 (\%95 Cl:0,63-1,0 $\mathrm{p}=006$ ) ve 24. Cys C. için 0,867 (95\% Cl: 0,00-1,00 p: 0,004) idi. Bu nedenle, 6 . saat NGAL ve 24. saat Cys C değerleri $A B H$ teşhisi için tanısal değere sahiptir.

Sonuç: Çalışmamıza göre, 6. saatte NGAL ve 24. saatte Cys C düzeyleri, CPB-ABH erken teşhisi için güçlü bir tanısal değere sahiptir.

Anahtar kelimeler: Kardiyopulmoner Bypass; akut böbrek hasarl; neutrophil gelatinase-associated lipocalin; sistatin C

Sorumlu Yazar": Okan Yıldız, Sağlık Bilimleri Üniversitesi Mehmet Akif Ersoy Eğitim Araştırma Hastanesi, Çocuk Kalp Damar Cerrahisi Kliniği, İstanbul/TÜRKIYE

E-posta: okanyildiz27@hotmail.com

ORCID: https://orcid.org/0000-0002-6192-3111

Gönderim: 03.09.2018 Kabul: 31.01.2019

Doi: $10.18663 /$ tjcl.456033 


\section{Abstract}

Aim: The development of acute kidney injury (AKI) after cardiopulmonary bypass (CPB) is associated with increased rates of mortality and morbidity. The identification of reliable biomarkers that allow earlier diagnosis of AKI in the postoperative period may increase the success of therapeutic interventions. The aim of our present study was to measure neutrophil gelatinase-associated lipocalin (NGAL) and cystatin $C(C y s C)$ levels and to test the accuracy and reliability as an early biomarker.

Material and Methods: The study was designed as a prospective observational study, comparing creatinine, NGAL, and Cys $\mathrm{C}$ levels in patients who develop AKI or not after heart surgery using CPB. Forty-three patients met the inclusion criteria. We obtained blood samples for NGAL and Cys $C$ at two predetermined time-points (6 and 24 hours) after the initiation of $\mathrm{CPB}$.

Results: According to the AKIN classification, 8 patients (44\%) developed AKI (AKI1 groups) and 35 (56\%) did not (nonAKI). The areas under the receiver operating characteristic curve (AUCROC) values were calculated for all parameters. AUCROC value was 0.81 (95\% Cl: 0, 63 to 1, 00) for 6th hours NGAL and 0.867 (95\% Cl: 0, 00-1, 00, p: 0.004) for 24th Cys C. Therefore, NGAL measured in 6th hours and 24th Cys C, have diagnostic value for early diagnosis of acute kidney injury.

Conclusion: Based on our study, NGAL levels measured in 6th hour, and Cys Clevels measured in the 24th hour have high predictive value for early diagnosis for CPB-ABH.

Keywords: Cardiopulmonary bypass; acute kidney injury; neutrophil gelatinase-associated lipocalin; cystatin C

\section{Giriş}

Kalp cerrahisinde en önemli postoperatif sorunlardan biri akut böbrek hasarıdır $(A B H)$. Erken başlangıçlı $A B H$ mortalite ve morbidite üzerine direkt etkilidir [1]. Yoğun bakım ünitesindeki (YBÜ) en büyük sorunlardan biri, $A B H ' n i n$ geç tanınması ve tedavisinde gecikme yaşanmasıdır. Tüm bu nedenlerden dolayı $A B H '$ 'nin daha erken saptanması için yeni biyobelirteçler araştııımaktadır [2,3]. Bunlardan biri olan neutrophil gelatinaseassociated lipocalin (NGAL); kan veya idrarda hali hazırda mevcut değildir. Proksimal tübül epitelyum hasarında aktif olarak nötrofillerden sentezlenerek kanda ölçülebilir hale gelmektedir. Diğer bir biyobelirteç olan sistatin C (Cys C) ise tüm çekirdekli hücreler tarafından üretilir ve glomerüler filtrasyon yoluyla atılır. Serum değerleri glomerüler filtrasyon hızına (GFR) karşlık gelmektedir ve yüksek kan değerleri $A B H$ 'ye işaret etmektedir [4]. NGAL ve Cys C'nin $A B H$ tanısı için erken biyobelirteç olduğunu gösteren çalışmalar vardır [5-9]. Ancak, bu belirteçlerin kardiyopulmoner bypass (CPB) uygulanmış erişkinlerdeki tanısal değeri net olarak ortaya konamamış olup, iki belirtecin beraber değerlendirildiği çalışma sayısı azdır. Bu çalışmanın amacı plazma NGAL ve serum Cys $C$ seviyelerini ölçmek ve $A B H$ tespitinde erken biyobelirteç olarak doğruluk ve güvenilirliği test etmektir.

\section{Gereç ve Yöntemler}

Çalışma, CPB kullanılarak uygulanan kalp cerrahisi sonrası ABH gelişen hastalarda $\mathrm{s} C r$, NGAL ve Cys $C$ düzeylerini karşılaştıran prospektif gözlemsel bir çalışma olarak tasarlandı. Hastane etik kurul onayı ve hasta onamları alındıktan sonra; Hacettepe Üniversitesi Tıp Fakültesi Kalp ve Damar Cerrahisi Anabilim dalında Nisan 2010- Eylül 2010 tarihleri arasında elektif açık kalp cerrahisi uygulanan 43 hasta çalışmaya dâhil edildi. 18 yaşından küçük olan, acil operasyona alınan (hastaneye yatışından sonraki ilk 24 saatte operasyona alınan), ameliyat öncesi bilinen bir böbrek hastalığı olan ve/veya operasyon öncesi $\mathrm{s} C r$ değerleri $1,5 \mathrm{mg} / \mathrm{dL}$ 'nin üzerinde olan hastalar çalışmaya dâhil edilmedi. Her hastadan bilgilendirilmiş onam alındı. Çalışmada Helsinki Bildirgesi'nin kuralları uygulandı.

Renal profil (BUN, $\mathrm{SCr}$ ) ameliyat öncesi, postoperatif sıfırıncı, birinci ve ikinci günlerde bir defa ölçüldü. Tüm hastalar için intraoperatif ve postoperatif olaylar ve laboratuar incelemeleri kaydedildi. Glomerüler filtrasyon oranı (GFR), Renal Hastalık formülündeki Diyetin Modifikasyonu [10] kullanılarak hesaplandı.

Istatistiksel kıyaslamaların yapılmasından önce hastaların ABH tanısı için 6. ve 24. saat Acute Kidney Injury Network (AKIN, Tablo 1) sınıflamaları ayrı hesaplandı [11]. Geleneksek biyobelirteçler kullanıldığı için ABH gelişen hasta grubu 24.saat değerlerine göre oluşturuldu. Hastalar AKIN kriterlerine göre iki gruba ayrıldı ( $\mathrm{BBH}$ gelişen ve $\mathrm{ABH}$ gelişmeyen). 


\section{Cerrahi Prosedürler}

Tüm hastalara, indüksiyonda Etomidat 0,4 mg/kg, Fentanil 1 $\mu \mathrm{g} / \mathrm{kg}$, Veküronyum bromür $0,1 \mathrm{mg} / \mathrm{kg}$ kullanıldı. Anestezi idamesinde, CPB başlangıcına kadar \%50 oksijen ve \%50 hava karışımı içinde MAK (Minimal Alveolar Konsantrasyon) değeri 1 olacak şekilde Sevoflurane ve Remifentanil 0,25-0,5 $\mu \mathrm{g} / \mathrm{kg} / \mathrm{dk}$ infüzyon uygulandı. Non-pulsatil CPB akımı 2,4 $\mathrm{ml} / \mathrm{m} 2$ ve ortalama perfüzyon basıncı $40-60 \mathrm{mmHg}$ olacak şekilde sağlandı. CPB sırasında orta derecede hipotermi (2832 C) uygulandı. Hct seviyesi \%20 üzerinde tutuldu. Aortik kros klemp konulduktan sonra $15-20 \mathrm{ml} / \mathrm{kg}$ potasyumlu soğuk kan kardiyoplejisi ve beraberinde soğuk topikal salin ile kardiyak arrest oluşturuldu. Cerrahi girişimin bitişini takiben anestezi amaçlı kullanılan ilaçlar kesilerek hasta entübe olarak yoğun bakım ünitesine götürüldü.

Entübasyon sonrası takılan sonda ve idrar akımı ölçüm sistemi ile saatlik idrar çıkışı takip edildi. Kristalloid solüsyon $1 \mathrm{ml} / \mathrm{kg} /$ saat olarak idame sıvı tedavisi başlandı. Saatlik idrar miktarının $20 \mathrm{cc} / \mathrm{saat}^{\prime}$ in $(0,5 \mathrm{ml} / \mathrm{kg})$ altına düşmesi ve bunun 2 saat devam etmesi oligüri olarak değerlendirildi. Diüretik verilmeden önce kardiyak debinin optimize edilmesi için hastanın volüm durumu değerlendirildi. Uygun sıvı durumuna rağmen oligüri varsa $20 \mathrm{mg}$ furosemid intravenöz olarak yapıldı. Tedaviye devam ediyor ise dozlar artırılarak tekrar edildi veya furosemid perfüzyonu $(0,1-0,5 \mathrm{mg} / \mathrm{kg} / \mathrm{saat})$ başlandı. YBÜ hastalarda meydana gelen hipotansiyon durumlarında $(O A B<50 \mathrm{mmHg})$ sırası ile kristalloid ve kolloid sıvılar, dopamin, hemodinamiyi bozan bradikardi durumlarında ise atropin kullanıldı. Hct değeri \%25'in üstünde olacak şekilde ihtiyaç duyulduğunda kan transfüzyonu yapıldı.

\section{Örneklerin toplanması ve değerlendirme}

NGAL ve Cys C için CPB başlatılması sonrası 6. ve 24. saatte kan örnekleri alındı. Numuneler santrifüj edildi ve daha sonra nihai analizler için $-40^{\circ}$ C'de saklandı. Human Lipocalin-2/ NGAL ELISA kiti ve Cystatin C ELISA kiti $\left({ }^{\circledR}\right.$, BioVendor Research and Diagnostic Products, Brno, Czech Republic) kullanılmıştır. Çalışmalar Hacettepe Üniversitesi Tıp Fakültesi Hastanesi Laboratuarı'nda gerçekleştirilmiştir.

\section{İstatistiksel Analiz}

Araştırmada kullanılacak analiz yöntemlerinin belirlenmesi amacıyla Kolmogorov-Smirnov ve Shapiro-Wilk normallik testleri uygulandı. Araştırmada, grup karşılaştırmaları, MannWhitney $U$ testi ile değerlendirildi. Ayrıca kategorik değişkenler arasındaki dağılımlar ki-kare analizi ile test edildi. Üzerinde durulan değişkenlerin (6. saat $\mathrm{SCr}$, NGAL, Cys $C$ ve 24. saat $\mathrm{SCr}$, NGAL, Cys C) hastalığı ayırma kabiliyetleri ROC ile araştırıldı (AUCROC ve \%95 güven aralıkları ile değerlendirildi). AUCROC değerleri, 0,90-1,0 mükemmel, 0,75-0,89 iyi, 0,75-0,50 zayıf ve $<0,50$ tanısal değeri yok olarak tanımlanmıştır [12]. Analizlerin gerçekleştirilmesi için SPSS 15.0 paket programı kullanıldı, istatistiksel anlamlılık sınırı olarak $p<0,05$ seçildi. Sürekli değişkenler ise ortanca (min.-maks.) şeklinde özetlendi.

\section{Bulgular}

Hastaların yaş ortalaması 56,6 \pm 13,02, vücut kitle indeksi 27,7 $\pm 4,7$ idi. 24 erkek (\% 56) ve 19 kadın (\% 44) hasta vardı. 16 (\% 37) hasta 60 yaşın üzerindeydi. 24. saat AKIN kriterlerine göre $8(\% 18,6)$ hastada $\mathrm{ABH}$ tespit edildi. 8 hastanın tümü evre 1 (Tablo 1) olarak sınıflandırıldı ve klinik olarak ilerleme gözlenmedi. $\mathrm{ABH}$ gelişen hastalara mayi kısıtlanarak ve nefrotoksik ilaçlardan kaçınılarak tedavi uygulandı; yakın laboratuar ve klinik takip uygulanarak izlem yapıldı. Özel bir medikal tedavi uygulanmadı.

\begin{tabular}{|c|c|c|}
\hline Evre & SCr Kriterleri & İdrar çıkışı Kriterleri \\
\hline 1 & $\begin{array}{l}\mathrm{SCr} \text { 'de } \geq 26,5 \mu \mathrm{mol} / \mathrm{L}(\geq 0,3 \\
\mathrm{mg} / \mathrm{dL}) \text { artış / bazal değere } \\
\text { göre } 1,5-2 \text { kat artış }\end{array}$ & $\begin{array}{l}6 \text { saat için }<0,5 \mathrm{~mL} / \\
\mathrm{kg} / \mathrm{st}\end{array}$ \\
\hline 2 & $\begin{array}{l}\text { SCr'de bazal değere göre } \\
>2-3 \text { kat artış }\end{array}$ & $\begin{array}{l}12 \text { saat için }<0,5 \mathrm{~mL} / \\
\mathrm{kg} / \mathrm{st}\end{array}$ \\
\hline 3 & $\begin{array}{l}\text { SCr'de bazal değere göre } \\
>3 \text { kat artış / SCr'de akut } 44 \\
\mu \text { mol/L (0,5 mg/dL) bir artış } \\
\text { ile beraber } \geq 354 \mu \mathrm{mol} / \mathrm{L} \text { ( } \geq 4 \\
\mathrm{mg} / \mathrm{dL} \text { ) olması / RRT ihtiyacı }\end{array}$ & $\begin{array}{l}24 \text { saat için }<0,3 \mathrm{~mL} / \mathrm{kg} / \\
\text { st / } 12 \text { saat için anüri }\end{array}$ \\
\hline \multicolumn{3}{|c|}{$\begin{array}{l}\text { ABH, akut böbrek hasarı; GFR, glomerüler filtrasyon hızı; RRT, renal } \\
\text { replasman tedavisi; SCr, serum kreatinin düzeyi. }\end{array}$} \\
\hline
\end{tabular}

$\mathrm{ABH}$ gelişen ve gelişmeyen grup arasındaki preoperatif, intra ve postoperatif verilerin karşılaştırılması Tablo 2'de verilmiştir. Preoperatif faktörler arasında sadece atriyal fibrilasyon varlığı $(p=0,02)$ artmış $A B H$ insidansı ile ilişkili bulundu. Preoperatif sCr seviyesi ve GFR değişkenleri arasında istatistiksel olarak anlamlı bir ilişki saptanmadı. Operasyon tipine bakılmaksızın intraoperatif faktörler arasında kros klemp süresi (dk) $\mathrm{ABH}$ insidansı ile ilişkili bulundu $(p=0,026)$. Postoperatif veriler ile ilgili olarak YBÜ' de inotropik ajan kullanımı $(p=0,004)$ ve revizyon gereksinimi $(p=0,034)$ dışında $A B H$ ile ilişkili bir faktör tespit edilemedi. Çalışma süresince mortalite yoktu. Entübasyon süreleri, yoğun bakımda ve hastanede kalış süreleri $\mathrm{ABH}$ gelişen grupta daha yüksek olmasına rağmen, bu durum istatistiksel anlamlılık göstermedi ( $p>0,05)$ (Tablo 2). 


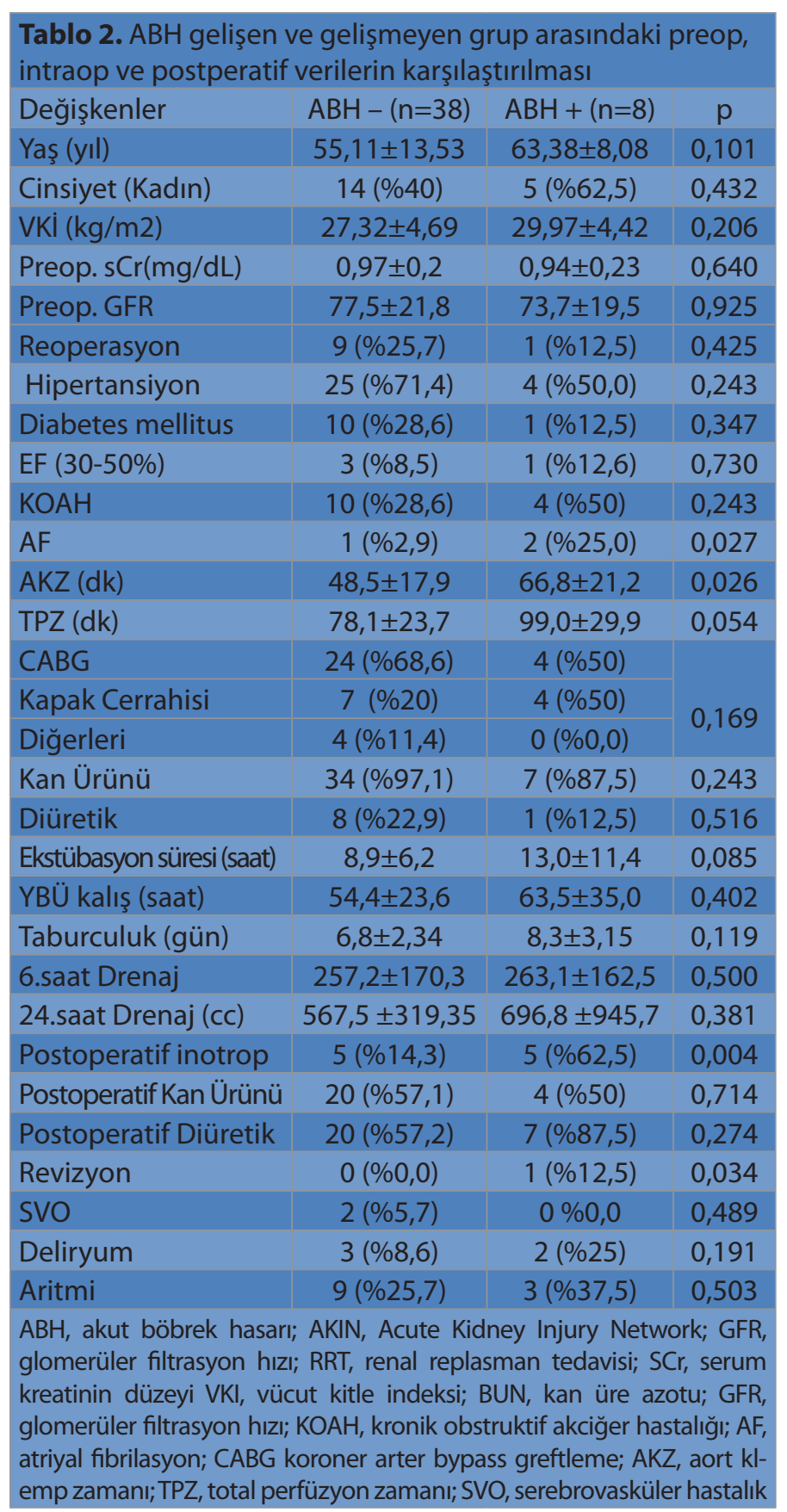

\section{NGAL ve Cys C}

$\mathrm{ABH}$ gelişen hastaların gelişmeyen hastalara göre, $\mathrm{CPB}$ sonrası 6. saatte alınan NGAL seviyelerinin belirgin yüksek olduğu, bu yüksekliğin 24.saat alınan NGAL düzeylerinde azalarak devam ettiği tespit edildi (Tablo 3). ABH gelişen hastaların gelişmeyen hastalara göre, CPB sonrası 6. saatte alınan Cys $C$ seviyelerinin az miktarda yüksek olduğu, bu yüksekliğin 24. saat alınan Cys C düzeylerinde belirgin artarak devam ettiği tespit edildi (Tablo 3).

24. saat AKIN sınıflamasına göre 6. saat SCr, GFR, NGAL ve Cys C için AUCROC hesaplandı (Tablo 4) ve değerleri sırasıyla
0,50, 0,46, 0,81, 0,66 olarak tespit edildi. Bu değerler içerisinde sadece NGAL için hesaplanan AUCROC: 0,81 değeri istatistiksel olarak anlamlı çıktı $(p=0,006)$. Diğer değerler için hesaplanan AUCROC değerleri istatistiksel olarak anlamlı sonuçlar vermedi ( $p>0,05)$. Youden analizi kullanılarak anlamlı çıkan tek değer olan NGAL için hesaplanan eşik değeri ise $2,883 \mathrm{ng} / \mathrm{ml}$ olarak tespit edildi. Yani bu değerin üstünde ölçülen NGAL; $A B H$ için bağımsız erken bir belirteç olarak kabul edildi.

\begin{tabular}{|c|c|c|c|c|}
\hline Biyobelirteç & $\begin{array}{l}\text { Tüm has- } \\
\text { talar n:43 }\end{array}$ & $\begin{array}{l}\text { ABH olma- } \\
\text { yan n:35 }\end{array}$ & $\begin{array}{c}\text { ABH olan } \\
n: 8\end{array}$ & $p$ \\
\hline NGAL 6 st (ng/ml) & $3,05 \pm 1,3$ & $2,7 \pm 1$ & $4,4 \pm 1,6$ & ,006 \\
\hline NGAL 24 st (ng/ml) & $1,9 \pm 0,78$ & $1,9 \pm 0,73$ & $2,2 \pm 0,78$ & ,365 \\
\hline Cys C 6 st (ng/ml) & $934 \pm 278$ & $901 \pm 249$ & $1081 \pm 362$ &, 156 \\
\hline Cys C 24 st (ng/ml) & $1104 \pm 264$ & $1050 \pm 234$ & $1338 \pm 275$ & 015 \\
\hline
\end{tabular}

24.saat AKIN sınıflamasına göre 24.saat sCr, GFR, NGAL ve Cys C için AUCROC hesaplandı (Tablo 4) ve değerleri sırasıyla $0,85,-0,16(+0,84), 0,60,0,779$ olarak tespit edildi. Bu değerler içerisinde sadece NGAL için hesaplanan AUCROC: 0,60 değeri istatistiksel olarak anlamlı sonuçlar vermedi ( $p>0,05)$. SCR, GFR ve Cys $C$ için hesaplanan AUCROC değerleri ise istatistiksel olarak anlamlı sonuçlandı (sırasıyla $p=0,008, p=0,004, p=0,015$ ). Youden analizi kullanılarak çıkan sonuçlar için hesaplanan eşik değerleri ise sCr:1,040 mg/dL, GFR:69 (mL/dk/1,73 m²), Cys $\mathrm{C}: 1476,9 \mathrm{ng} / \mathrm{mL}$ olarak tespit edildi.

\begin{tabular}{|c|c|c|c|}
\hline Test & AUCROC & $p$ & $\mathrm{Cl} \% 95^{*}$ \\
\hline 6.saat SCr (mg/dL) & 0,50 & 1,000 & $0,22-0,77$ \\
\hline 6.saat GFR (ml/dk/1.73 $\left.\mathrm{m}^{2}\right)$ & 0,46 & 0,767 & $0,20-0,73$ \\
\hline 6.saat NGAL (ng/ml) & 0,81 & 0,006 & $0,61-1,0$ \\
\hline 6.saat Cys C (ng/ml) & 0,66 & 0,156 & $0,41-0,91$ \\
\hline 24.saat SCr (mg/dL) & 0,80 & 0,008 & $0,59-1,00$ \\
\hline 24.saat GFR (ml/dk/1.73 $\left.\mathrm{m}^{2}\right)$ & 0,16 & 0,004 & $0,0-0,34$ \\
\hline 24.saat NGAL (ng/ml) & 0,60 & 0,365 & $0,38-, 82$ \\
\hline 24.saat Cys C (ng/ml) & 0,77 & 0,015 & $0,56-, 98$ \\
\hline \multicolumn{4}{|c|}{$\begin{array}{l}\text { ABH, akut böbrek hasarı; AKIN, akut böbrek hasarı ağı; GFR, } \\
\text { glomerüler filtrasyon hızı; SCr, serum kreatinin düzeyi; NGAL, Neu- } \\
\text { trophil gelatinase-associated lipocalin, Cys C, Sistatin C; AUCROC, } \\
\text { eğri altında kalan alan, } \\
\text { *Cl \%95 Ortalamanın \%95 güven aralığı: Geniş bir güven aralığı, } \\
\text { tahminimizin hassas olmadığını gösterir. Güven aralığının dar } \\
\text { olması durumunda tam tersi geçerlidir }\end{array}$} \\
\hline
\end{tabular}

\section{Tartışma}

CPB sonrası $\mathrm{ABH}$ önemli mortalite ve morbidite nedeni olarak karşımıza çıkmaktadır $[2,13,14]$. Daha güncel olarak, geçici azoteminin (başlangıcından sonra 72 saat içinde, hızlı bir şekilde 
düzelen $A B H$ ) bile masum bir durum olmadığı ve mortalite için bağımsız bir risk faktörü olduğu bildirilmiştir [15]. SCr'de 0,5 $\mathrm{mg} / \mathrm{dL}$ artışın hasta bakım maliyetlerinin yükselmesine neden olabilmektedir [16]. Çalışmamızda mortalite izlenmedi. Ancak $\mathrm{ABH}$ gelişen hastalarda mekanik ventilatör, YBÜ ve hastanede kalış süresi gelişmeyen hastalara göre daha uzun bulundu. Ama bu durum istatistiksel olarak kanıtlanamadı.

CPB sonrası $\mathrm{ABH}$ farklı patofizyolojik mekanizmaların etkileşimi sonucudur. En önemli iki neden; hasta kaynaklı nedenler ve CPB'dir [2, 14, 17]. Çalışmamızda, $A B H$ gelişmesinde hasta kaynaklı en önemli riskler olan [2]; yaş, kadın cinsiyet, preoperatif SCr seviyesi ve GFR açısından istatistiksel olarak anlamlı sonuçlar bulunamadı. Sadece preopetarif AF ritmi ABH için istatistiksel olarak bağımsız bir risk sayıldı. Reoperasyon ve yapılan ameliyatın türü $A B H$ açısından istatistiksel olarak anlamlı sonuç vermedi. AKZ, revizyon uygulanması ve ameliyat sonrası inotropik ilaç kullanımı $A B H$ için istatistiksel olarak bağımsız birer risk sayıldılar. Önemli bir faktör olan CPB süresi ise $\mathrm{ABH}$ gelişen grupta daha yüksek olmasına rağmen istatistiksel olarak sınırda bir anlamsızlık söz konusu oldu.

Birçok çalışmanın göstermiş olduğu gibi CPB sonrası $A B H$ tanısı için erken bir belirteç yoktur. AKIN ve diğer sistemler geleneksel biyobelirteçleri (sCr, GFR idrar çıkış miktarı) kullanırlar ve bunlar gerçek zamanlı yükselmezler. Süreç devam ettikçe, ilerleyen zamanda yükselme yaparlar ve özgünlük kusurları vardır $[14,18]$. Çalışmamızda, ABH gelişen hastalarda geleneksel biyobelirteçlerin tanısal değerleri ölçüldü. 6. ve 24.saat $\mathrm{sCr}$ ve GFR için AUCROC hesaplandı. Erken prognostik değerlendirme yapmak içinde AUCROC değerleri zayıf kaldı. Bu sonuçlara göre $s \mathrm{Cr}$ ve GFR ABH erken tespiti için tanısal değere sahip değildir ve ikisi de 24. saat ve sonrası tanısal anlamlılık kazanmaktadır.

$\mathrm{Bu}$ sonuçlara ışığında, çalışmamız ABH'nin erken tespiti için yardımcı olabilecek başka belirteçlere ihtiyacımız olduğunu göstermiştir. Bu yeni belirteçler içinde NGAL, en çok çalışılan ve en çok umut verendir [14]. CPB ilişkili ABH açısından, yetişkin ve pediatrik hastalarda yapılan çalışmalarda bağımsız bir belirteç olarak bulunmuştur $[15,19]$. 426 erişkin hasta ile yapılan büyük prospektif bir çalışmada [20], TPZ ve AKZ ile idrardaki NGAL'in yükselmesi arasında korelâsyon bulunmuştur. TPZ ve $A K Z$ renal hipoperfüzyonun önemli bir nedenidir ve $A B H$ gelişmesi için birer risk faktörü oldukları bildirilmiştir [21]. SCr ise TPZ ve AKZ ile bir korelâsyon göstermemiştir. Başka bir çalışmada [6], 2. saatte NGAL düzeyinin sadece $A B H$ tahmini için son derece duyarlı ve özgül olduğu, aynı zamanda 12. saatte NGAL düzeyinin hastanede kalış süresinin bir belirteci olduğunu belirtilmiştir.
Başka bir çalışmada, 2. saat idrar NGAL düzeyinin $A B H$ şiddetinin ve süresinin, hastanede kalış süresinin, RRT ihtiyacının ve 196 tane CPB uygulanan çocukta mortalitenin gerçek bir belirteci olduğu bulunmuştur [7]. Bununla beraber, güncel bir çalışmada [22], öncekilerle çelişen sonuçlar ortaya çıkmıştır. NGAL'in ABH için özel bir test olmadığı, uygun bir belirteç olamayacağına sonucuna varılmıştır. Bunu destekleyen başka bir çalışmada, NGAL operasyon öncesi normal böbrek fonksiyonlarına sahip hastalarda erken bir belirteç olduğu, operasyon öncesi GFR (<60 mL/dk) olan hastalarda gösterge olamayacağı sonucuna varılmıştır [23]. Benzer bir çalışma ve derlemede, kalp cerrahisi geçiren erişkin hastalarda tanıda daha az tutarlı bulunmuştur ve farklılığın nedeni tam olarak açıklanamamıştır [6,12]. Çalışmamızda, 6. saat NGAL erken $A B H$ gelişmesi açısından bağımsız bir belirteç olarak bulunmuştur. $A B H$ ile belirgin bir korelâsyon göstermektedir. 24. saat NGAL ise $A B H$ gelişmesi açısından bağımsız bir belirteç değildir. NGAL düzeylerinin postoperatif 6 saatte hızlı yükselmesi ve 24 saatte düşme göstermesi, daha önceden bildirildiği gibi, NGAL için kalp cerrahisi ile ilişkili tübüler hasarın bir belirteci olabileceğini düşündürmektedir [4]. SCr temelli $\mathrm{ABH}$ tanısı olmayan hastalarda NGAL konsantrasyonlarındaki artış, konvansiyonel sCr temelli kriterlerle tespit edilemeyen böbrek hasarı gelişen bireyleri gösterebilir.

Cys $C$ ise GFR için potansiyelli bir biyobelirteç olup $\mathrm{sCr}$ 'den farklı olarak yaştan, cinsiyetten ve kas kitlesinden etkilenmemektedir. Tüm çekirdekli hücreler tarafından sentezlenir ve kas tarafından üretilen kreatininden farklı olarak, bireylerdeki ve kas kütlesindeki farklılıklardan etkilenmez [24]. Bu yüzden Cys $C$ ise GFR' nin değerlendirilmesinde çekici bir belirteçtir. Cys $C$ için erken çalışmalar çok değişken sonuçlar vermişlerdir. $B u$ yüzden $A B H$ erken belirteci olması ile ilgili durum açık değildir [25]. CPB uygulanan 372 çocuk hastadan prospektif olarak toplanan serum $C y s$ seviyeleri $C P B$ sonrası 12. saatte $A B H$ gelişen hastalarda belirgin olarak yüksek olduğu ve bu yüksekliğin 24 saat boyunca kaldığı bildirilmiştir. Bu çalışmada Cys C ve SCr karşılaştırılmıştır. Cys $C$ daha erken ve daha doğru bir biyobelirteçler olduğu gösterilmiştir. 6. ve 24 . saat bakılan Cys $\mathrm{C} A B H$ gelişmesi açısından bağımsız belirteç olarak bulunmadı. 6. saat Cys C'nin AUCROC değerleri daha yüksek bulundu. Bu verilere göre Cys C SCr'ye göre daha erken yükselen bir belirteç değildir. Ama daha yüksek tanısal değere sahip bir biyobelirteç olduğu istatistiksel olarak gösterilmiştir.

6. saat NGAL $A B H$ için erken belirteç olarak güçlü bir tanısal değere sahiptir. Bu durum 24. saat bakılan NGAL için geçerli değildir. Tam tersi olarak Cys C erken gösterge olma gücü 
zayıf, 24. saat gösterge gücü ise kuvvetli bir tanısal test olarak değerlendirilmiştir. Aynı zamanda Cys C'nin SCr'ye göre daha güçlü bir tanısal değere sahip olduğu saptanmıştır. Bu yüzden 6. saat NGAL ve 24. saat Cys C beraber değerlendirilirse tek başlarına olandan daha güçlü bir tanısal güze sahip olabilirler. Homojen, hasta gruplu çalışmalarda AUCROC değerleri $>0,90$ olarak bulunurken, daha heterojen olan (erişkin kalp cerrahisi ve genel YBÜ hastaları) gruplar arasında yapılan çalışmalarda çok daha düşük AUCROC değerleri bulunmuştur [26]. Çalışmamız kalp cerrahisi uygulanan erişkin hasta grubunu içermektedir. Pediatrik gruplara göre çok daha heterojen bir gruptur. Buna rağmen NGAL AUCROC değeri erken dönemde 0,81 bulunmuştur. Aynı zamanda Cys ile ilgili yapılmış nispeten daha az çalışmadan elde edilen bilgilerle karşılaştırılacak olursak daha net bilgilere ulaşılmıştır.

Bazı değerler istatistiksel olarak sınırda anlamsız çıkmıştır. Bu durum örneklem sayımızın azlığı ve $A B H$ olan grubun sayısal küçüklüğü ile ilişkili olabilir. Sayının artması durumunda bazı konular ile ilgili daha anlamlı sonuçlar almak muhtemeldir.

\section{Sonuç}

Sonuç olarak, NGAL CPB ABH'nin erken belirleyicileri olarak düşünülebilir. $A B H$ 'nin konvansiyonel tanımlarına dayanan klinik tanıdan önce 24 saate kadar $\mathrm{ABH}$ teşhisine izin verir. Yüksek riskli hastalar, geri dönüşümsüz yaralanma meydana gelmeden önce başlatılacak erken tedavilerden fayda sağlayabilirler. Cys C ile ölçülen GFR daha sağlıklı sonuçlar verebilir. Bu konu ile ilgili çalışmaların, çok merkezli, multidisipliner, daha fazla hasta sayısı içeren heterojen grupların yer aldığı, biyobelirteçlerin ayrı ayrı değerlendirilmesi yerine kombine şekilde denendiği şekilde olmasını öneriyoruz. Yazının bir başka yere yayın için gönderilmediğinin beyanı: Bu çalışmanın içindeki materyalin tamamı ya da bir kısmının daha önce herhangi bir yerde yayınlanmadığını ve hâlihazırda da yayın için başka bir yerde değerlendirilmede olmadığını beyan ederim.

\section{Maddi Destek ve Çıkar illişkisi}

Çalışmayı maddi olarak destekleyen kişi/kuruluş yoktur ve yazarların çıkara dayalı bir ilişkisi yoktur.

\section{Kaynaklar;}

1. Thakar CV, Worley S, Arrigain S, Yared JP, Paganini EP. Influence of renal dysfunction on mortality after cardiac surgery: modifying effect of preoperative renal function. Kidney Int 2005; 67: 1112-19.

2. Kumar AB, Suneja M. Cardiopulmonary bypass-associated acute kidney injury. Anesthesiology 2011; 114: 964-70.
3. Erdoğan MB, Demirpençe Ö, Yıldırım M. Kardiyovasküler Cerrahi Sonrası Gelişen Akut Böbrek Yetmezliğinin Tanısında Kullanılan Erken Dönem Belirteçler. ACU Sağlık Bil Derg 2016:14-19

4. Sudi-Ghonemy TA, Amro GM. Plasma neutrophil gelatinaseassociated lipocalin (NGAL) and plasma cystatin C (CysC) as biomarker of acute kidney injury after cardiac surgery. Saudi J Kidney Dis Transpl 2014; 25: 582-88

5. Mishra J, Dent C, Tarabishi R et al. Neutrophil gelatinaseassociated lipocalin (NGAL) as a biomarker for acute renal injury after cardiac surgery. Lancet 2005; 365: 1231-38.

6. Dent $\mathrm{CL}, \mathrm{Ma} \mathrm{Q}$, Dastrala $\mathrm{S}$ et al. Plasma neutrophil gelatinaseassociated lipocalin predicts acute kidney injury, morbidity and mortality after pediatric cardiac surgery: a prospective uncontrolled cohort study. Crit Care 2007; 11: 127.

7. Bennett $\mathrm{M}$, Dent $\mathrm{CL}$, Ma $\mathrm{Q}$ et al. Urine NGAL predicts severity of acute kidney injury after cardiac surgery: a prospective study. Clin J Am Soc Nephrol 2008; 3: 665-73.

8. Soni SS, Pophale R, Ronco C. New biomarkers for acute renal injury. Clin Chem Lab Med 2011; 49: 1257-63.

9. Haase M, Bellomo R, Devarajan P et al. Novel biomarkers early predict the severity of acute kidney injury after cardiac surgery in adults. Ann Thorac Surg 2009; 88: 124-30.

10. Sarnak MJ, Levey AS. Cardiovascular disease and chronic renal disease: a new paradigm. Am J Kidney Dis 2000; 35: 117-31.

11. Mehta RL, Kellum JA, Shah SV et al. Acute Kidney Injury Network: report of an initiative to improve outcomes in acute kidney injury. Crit Care 2007; 11: 31.

12. Ray P, Le Manach $Y$, Riou B, Houle TT. Statistical evaluation of a biomarker. Anesthesiology 2010; 112: 1023-40.

13. Lewington A, Kanagasundaram S. Renal Association Clinical Practice Guidelines on Acute Kidney Injury. Nephron Clinical Practice $2011 ; 118$ : 349-90.

14. Mariscalco G, Lorusso R, Dominici C, Renzulli A, Sala A. Acute kidney injury: a relevant complication after cardiac surgery. Ann Thorac Surg 2011; 92: 1539-47.

15. Uchino S, Bellomo R, Bagshaw SM, Goldsmith D. Transient azotaemia is associated with a high risk of death in hospitalized patients. Nephrol Dial Transplant 2010; 25: 1833-39.

16. Wagener G, Jan M, Kim M et al. Association between increases in urinary neutrophil gelatinase-associated lipocalin and acute renal dysfunction after adult cardiac surgery. Anesthesiology 2006; 105: 485-91. 
17. Garwood S. Cardiac surgery-associated acute renal injury: new paradigms and innovative therapies. J Cardiothorac Vasc Anesth 2010; 24: 990-1001.

18. Karadeniz Z, Tuncel Z, Yapıcı N et al. Akut Böbrek Hasarının Erken Tanısında Plazma NGAL (Neutrophil Gelatinase-Associated Lipocalin) Etkinliğinin Off-pump ve On-pump Kalp Cerrahisinde Karşılaştırılması. Göğüs-Kalp-Damar Anestezi ve Yoğun Bakım Derneği Dergisi 2013: 168-174

19. Tuladhar SM, Puntmann VO, Soni M, Punjabi PP, Bogle RG. Rapid detection of acute kidney injury by plasma and urinary neutrophil gelatinase-associated lipocalin after cardiopulmonary bypass. J Cardiovasc Pharmacol 2009; 53: 261-66.

20. Wagener G, Gubitosa G, Wang S, Borregaard N, Kim M, Lee HT. Urinary neutrophil gelatinase-associated lipocalin and acute kidney injury after cardiac surgery. Am J Kidney Dis 2008; 52: 425-33.

21. Fischer UM, Weissenberger WK, Warters RD, Geissler HJ, Allen SJ, Mehlhorn U. Impact of cardiopulmonary bypass management on postcardiac surgery renal function. Perfusion 2002; 17: 401-406.
22. Liangos $\mathrm{O}$, Tighiouart $\mathrm{H}$, Perianayagam MC et al. Comparative analysis of urinary biomarkers for early detection of acute kidney injury following cardiopulmonary bypass. Biomarkers 2009; 14: 423-31

23. Mcllroy DR, Wagener G, Lee HT. Neutrophil gelatinase-associated lipocalin and acute kidney injury after cardiac surgery: the effect of baseline renal function on diagnostic performance. Clin J Am Soc Nephrol 2010; 5: 211-19.

24. Dharnidharka VR, Kwon C,Stevens G. Serum cystatin $C$ is superior to serum creatinine as a marker of kidney function: A metaanalysis Am J Kidney Dis 2002; 40: 221-26

25. Mcllroy DR, Wagener G, Lee HT. Biomarkers of acute kidney injury: an evolving domain. Anesthesiology 2010; 112: 998-1004.

26. Lameire $\mathrm{NH}$, Vanholder RC, Van Biesen WA. How to use biomarkers efficiently in acute kidney injury. Kidney Int 2011; 79: 104 